\title{
Intraductal mono-octanoin for the direct dissolution of bile duct stones: experience in 343 patients
}

\author{
K R PALMER AND A F HOFMANN \\ From the Department of Medicine, University of California, San Diego, California, USA
}

\begin{abstract}
SUMmaRY The efficacy and safety of mono-octanoin, a cholesterol solvent for the direct dissolution of stones in the biliary tract, was assessed by collating case reports on 343 patients provided by 222 physicians who used the material between 1977 and 1983 . Most patients had previously undergone cholecystectomy, with common duct exploration, the majority within the preceding six weeks. In most, sphincterotomy was impossible or if carried out, had not induced stone passage. Stone dissolution was considered preferable to surgery, especially in patients who were frail, elderly, or had multiple medical problems. Treatment was unequivocally successful in 88 patients $(26 \%)$ and was a valuable adjunct to interventional treatment in another 29 subjects $(8 \%)$. In 70 patients $(20 \%)$, calculi became smaller, but remained within the biliary tree. Thus, mono-octanoin was judged to have been useful in $54 \%$ of patients. Treatment was ineffective in 124 cases $(36 \%)$. In the remaining 32 patients $(9 \%)$, treatment was aborted because of side effects. Such side effects were common, occurring in $67 \%$ of cases, and in $41 \%$ of patients they were multiple. Abdominal pain was the most common complication. Other side effects reported were nausea, vomiting, and diarrhoea. Side effects were usually dose related and responded to reduction in infusion rate. Side effects were life threatening in 12 patients $(5 \%)$, but there were no permanent sequelae and no deaths occurred. These data indicate that mono-octanoin is moderately effective, generally second line, but sometimes first line, treatment for retained biliary duct calculi.
\end{abstract}

Common bile duct calculi can be removed by endoscopic, percutaneous, or surgical means. In a minority of patients these approaches fail. This is usually because of technical difficulties, large stone size, or complicating medical problems. ${ }^{P}$ Direct infusion of bile duct stone solvents into the bile duct is a remaining therapeutic possibility in such patients. In addition, duct stones may be discovered by T-tube cholangiography within a few days after cholecystectomy. In such patients, stone solvents can be infused before the sinus tract has been formed, in which case mono-octanoin is an alternative to sphincterotomy. (Burhenne T-tract extraction cannot be carried out until a mature sinus tract has formed around the T-tube; this requires four to six weeks after placement of the T-tube.)

The practice of dissolving (cholesterol) bile duct stones by instilling organic cholesterol solvents into

Address for correspondence: A F Hofmann, MD, Department of Medicine, Division of Gastroenterology T-013, University of California, San Diego, La Jolla, California 92093 USA.

Received for publication 28 March 1985 the gall bladder was described nearly a century ago. ${ }^{2}$ Pribram $^{3}$ standardised the technique, and it was used commonly thereafter. ${ }^{4}$ Nonetheless, the technique gradually fell into disfavour because of the severity of side effects in some patients, as well as improvement in surgical techniques. ${ }^{5}$ In 1972, Admirand and Way reported that a micellar solution of sodium cholate would dissolve cholesterol gall stones rapidly in vitro and could be used safely and effectively in patients with bile duct stones. ${ }^{67}$ Early results of these workers and others ${ }^{8-11}$ were encouraging. Nonetheless, it was thought that success often resulted from the flushing effect per se of the cholate solution, as saline ${ }^{12}$ or a dilute heparin solution,,$^{13}$ which has no ability whatsoever to dissolve cholesterol, has also been reported to cause stone disappearance when infused into T-tubes. In addition, toxicity studies in primates indicated that cholate solutions caused severe tissue damage at the site of infusion. ${ }^{15}$

Thistle et al subsequently showed that monooctanoin, a semisynthetic vegetable oil, was a more 
effective gall stone solvent than cholate solution. ${ }^{16}{ }^{17}$ Since then, this group ${ }^{18}$ and a number of other groups ${ }^{19-29}$ have reported on the clinical application of this solvent for the treatment of bile duct stones. A proprietary preparation of monooctanoin, Capmul 8210 (now named Moctanin ${ }^{\mathrm{TM}}$ ), has been used for most studies; however, in one European study ${ }^{28}$ the material was modified by the addition of buffer and emulsifier. Although nominally mono-octanoin, Moctanin in fact contains about $70 \%$ of the 1-mono-ester of octanoic acid and about $30 \%$ of the di-ester ${ }^{30}$; the oil is an excellent cholesterol solvent $(12 \mathrm{~g} / 100 \mathrm{ml}$ or about $0 \cdot 3 \mathrm{M}){ }^{17}$

In the studies reported to date, the number of patients studied has been quite small. The justification for the present report are data for efficacy and safety from a much larger group of patients. The data presented here summarise the total available international experience for mono-octanoin which has been supplied by its original manufacturer.

\section{Methods}

\section{PATIENTS}

Mono-octanoin is an experimental drug and has been available only to registered physicians. Physicians, surgeons, and radiologists from the United States and Europe obtained mono-octanoin from the Division of Gastroenterology at the University of California, San Diego, with the sanction of the Food and Drug administration (FDA). Physicians were required to indicate that they understood the principles of its use, that they would use it only in inpatients and according to a standard protocol, that they would obtain approval of the protocol from their institutional review board, that they would obtain informed consent from the patient, that they would notify the sponsor immediately if untoward effects occurred, and that they would complete a standard case report form and return this to the drug sponsor at the end of their study. The uncommon practice of the FDA in permitting an experimental drug to be used widely by individual physicians is in keeping with the practice of the FDA to approve unlicensed drugs for use in patients whenever it is in the best interests of patient care.

Eligible patients had retained duct stones and direct access to the bile duct by T-tube, percutaneous transhepatic catheter, nasobiliary tube, or cholecystostomy catheter. Only patients with radiolucent gall stones were treated, as such stones are likely to be cholesterol stones, and stones with a low proportion of cholesterol do not dissolve in mono-octanoin. ${ }^{19}$ Patients with a grossly infected biliary tree were excluded, as well as patients with parenchymal liver disease, as mono-octanoin is hydrolysed to octanoic acid which is rapidly absorbed and metabolised in the liver. ${ }^{31}{ }^{32}$ Coincident medical illness, recent biliary tract surgery, or endoscopic procedures did not preclude monooctanoin treatment. The physician was questioned to ensure that during cholangiography, dye flowed freely into the duodenum; if not, the treatment was approved only when no other approach was possible.

\section{METHOD OF ADMINISTRATION}

Mono-octanoin was shipped to the pharmacy of each medical centre. In the majority of patients, mono-octanoin was used as the anhydrous oil after sterile filtration. In some patients, however, the compound was used as received; mono-octanoin is bacteriostatic, and cultures for bacteria have been negative. During the past year, we have recommended that the pharmacist adds water to the mono-octanoin ( $10 \%$ by volume) to decrease its viscosity and lower its freezing point. In vitro studies have indicated that the addition of water should not decrease the solubility of cholesterol in mono-octanoin,$^{33}$ and dissolution studies with model gall stones suggest that gall stones should dissolve more rapidly in mono-octanoin containing $10 \%$ water than in anhydrous mono-octanoin. ${ }^{30}$

Mono-octanoin warmed to approximately $37^{\circ} \mathrm{C}$ was infused through a T-tube, nasobiliary tube, percutaneous transhepatic catheter, or cholecystostomy tube into the biliary tract by using constant infusion pump or by gravity. In patients with an intact sphincter of Oddi and large common duct stones, precautions were taken to guard against the possibility that the stone might become impacted during mono-octanoin infusion and mono-octanoin would then be pumped into the biliary tract under pressure. Physicians were advised to place an overflow manometer in the tubing between the pump and the patient. A central venous pressure manometer was to be adjusted so that if the pressure exceeded $12 \mathrm{~cm}$ of mono-octanoin, the monooctanoin would overflow from the tube and not enter the patient. The initial infusion rate was 1 to 2 $\mathrm{ml} / \mathrm{h}$, and it was recommended that this should be increased to $5 \mathrm{ml} / \mathrm{h}$. Nonetheless, in some studies, the infusion rates were twice this rate. Because each millilitre of mono-octanoin dissolves $120 \mathrm{mg}$ of cholesterol, dissolution is likely to have occurred under 'sink' conditions - that is, the solvent was always almost completely unsaturated in cholesterol. In some patients, a concentric catheter was used, so that material could be infused even if a stone was impacted in the ampulla. ${ }^{34}$ In other patients, a two 
catheter arrangement was used to facilitate biliary drainage. ${ }^{21} 35$ As noted, however, physicians were advised that the use of mono-octanoin in patients with an obstructed common duct was quite hazardous, and such patients were approved only when no other therapeutic approach was possible. Cholangiograms were obtained before and at least at weekly intervals during the treatment period. Routine liver tests were monitored in most subjects.

\section{DEFINITION OF OUTCOME}

Outcome was defined in one of the following ways:

\section{A SUCCESSFUL THERAPY}

\section{Sole procedure}

Calculi disappeared from the biliary tract, and no contributory procedures were done.

\section{Adjunctive therapy}

Failed or incomplete endoscopic or percutaneous removal was followed by successful infusion therapy. Two patterns were distinguished: (a) a biliary sphincterotomy was unsuccessful in achieving passage of calculi. After the mono-octanoin infusion, cholangiography indicated that the stones had disappeared. (b) A Burhenne extraction through a mature T-tube sinus tract was initially unsuccessful. Infusion therapy then either fragmented the calculi or softened them, permitting the stones to be extracted through the $\mathrm{T}$-tube tract.

\section{Partially successful therapy}

Stones became smaller, but remained in the common bile duct. Additional surgical or endoscopic procedures were necessary to remove the duct stones.

B TREATMENT FAILURE

1 Stone size and number were unaffected by infusion of mono-octanoin.
2 Side effects caused the infusion to be abandoned, or to be aborted shortly after it was initiated. This included patients in whom infused mono-octanoin leaked around the infusion cannula.

\section{DATA BASE}

During the six year period, mono-octanoin was authorised for 831 physicians. Results of therapy were available from 222 of these physicians. The total number of patient reports was 377 , of which 343 were sufficiently complete for tabulation.

\section{STATISTICAL METHODS}

Data were analysed using an analysis of variance procedure followed by a least significant difference test.

CLINICAL CHARACTERISTICS OF PATIENTS

The mean age of the patients was 66 years, the range being from 17 to 98 years. The majority $(66 \%)$ were women.

Previous biliary surgery is summarised in Table 1. Most $(97 \%)$ subjects had undergone cholecystectomy with or without exploration of the common duct. Most patients presented with retained common bile duct calculi less than six months after surgery (recent biliary surgery - Table 2). Most of these were discovered by routine postoperative T-tube cholangiography. Eight patients were treated with mono-octanoin without complications less than two weeks after common duct exploration and, about $65 \%$ of patients were treated less than six weeks after a cholecystectomy.

Approximately one-third of subjects presented with retained common bile duct calculi more than six months after cholecystectomy (remote biliary surgery - Table 2). Many of these had undergone cholecystectomy several years previously, the longest period being 37 years.

A small group of subjects had not previously

Table 1 Status of biliary tract before mono-octanoin infusion

\begin{tabular}{|c|c|c|c|c|}
\hline \multirow[b]{2}{*}{ Initial status } & \multirow[b]{2}{*}{$\begin{array}{l}\text { No additional } \\
\text { procedures }\end{array}$} & \multicolumn{2}{|c|}{ Additional procedures* } & \multirow[b]{2}{*}{ Total } \\
\hline & & $\begin{array}{l}\text { Endoscopic } \\
\text { sphincterotomy }\end{array}$ & $\begin{array}{l}\text { Burhenne } \\
\text { extraction }\end{array}$ & \\
\hline $\begin{array}{l}\text { Recent biliary surgery } \\
\quad \text { (Cholecystectomy } \pm \text { common bile duct exploration) }\end{array}$ & 98 & 6 & 87 & 191 \\
\hline $\begin{array}{l}\text { Remote biliary surgery } \\
\text { (Cholecystectomy } \pm \text { common bile duct exploration) }\end{array}$ & 22 & 82 & 10 & 114 \\
\hline Cholecystectomy alone & 8 & 0 & 0 & 8 \\
\hline Gall bladder in situ & 0 & 14 & 0 & 14 \\
\hline Other ${ }^{+}$ & 8 & 8 & 0 & 16 \\
\hline Total & 136 & 110 & 97 & 343 \\
\hline
\end{tabular}

* Remaining patients had no additional procedures. $†$ See text. 
Table 2 Stone size and number

\begin{tabular}{llcrc}
\hline & \multicolumn{4}{l}{ Patients with stones of largest diameter $(\mathrm{no})$} \\
\cline { 2 - 5 } & \multicolumn{4}{l}{ Diameter of stone, $\mathrm{mm}$} \\
& $<10$ & $10-20$ & $>20$ & Total \\
\hline 1 stone & 40 & 60 & 46 & 146 \\
2 stones & 10 & 10 & 32 & 52 \\
3 stones & 16 & 15 & 7 & 38 \\
$>3$ stones & 20 & 67 & 20 & 107 \\
Total & 86 & 152 & 105 & 343 \\
\hline
\end{tabular}

undergone cholecystectomy, but had duct stones which could not be removed by an endoscopic procedure. These patients were a frail, elderly subgroup, and considered to be at high risk for surgery. Mono-octanoin was infused through a nasobiliary catheter in these patients. Eight elderly ill patients presented with fulminating septicaemia and underwent emergency cholecystostomy. Monooctanoin was subsequently infused through the cholecystostomy drain.

The remaining 16 patients were a heterogenous group. Six patients were found to have retained stones after choledochoduodenostomy; three patients had oriental cholangiohepatitis; one had Caroli's disease with multiple intrahepatic biliary stones; and the remaining subjects had undergone complicated biliary reconstructive surgery.

One third of the patients had undergone endoscopic biliary sphincterotomy with unsuccessful endoscopic gall stone retrieval. In another third, the Burhenne technique, in which a catheter is passed through a mature T-tube tract, had failed.

About one third of the patients had additional medical problems, and one third were over 75 years old. Many were frail and judged to be high risk surgical candidates. Significant cardiovascular disease was present in 80 patients, 18 patients had insulin requiring diabetes and 15 had severe chronic pulmonary disease.

\section{ROUTE OF INFUSION}

Mono-octanoin was infused into the biliary tract through a T-tube in 230 patients $(67 \%)$, by nasobiliary catheter in 82 patients $(24 \%)$, through the percutaneous transhepatic route in 23 patients (7\%), and through a cholecystostomy drain in eight patients $(2 \%)$.

\section{NUMBER AND SIZE OF CALCULI}

Stone size and number before mono-octanoin treatment are shown in Table 2. Mean stone diameter for the total group was $13.5 \pm 0.7 \mathrm{~mm}$ (SEM).

\section{Results}

EFFICACY OF TREATMENT (Table 3)

Unequivocally successful therapy, therapy judged to be a helpful adjunct, or partially successful therapy occurred in 187 patients $(55 \%)$. The mean infusion rate was similar in each outcome group. The major limiting factors were the failure of stones to dissolve or be flushed out as well as the development of side effects. The mean duration of therapy was longest in the partial success group, and, as would be anticipated, shortest in the aborted treatment group. There was no relationship between stone size and number and response.

\section{SERUM LIVER TESTS}

Serum alkaline phosphatase and aminotransferase concentrations were available in 261 patients before mono-octanoin infusion and in 173 patients at the completion of therapy. The majority of patients (69\%) had a raised serum alkaline phosphatase concentration, and about half had a raised aminotransferase concentration before mono-octanoin infusion. In general, the subsequent course of these serum enzyme concentrations was not related to the outcome of treatment. In subjects in whom treatment was unequivocally successful, alkaline phos-

Table 3 Efficacy of treatment of mono-octanoin in 343 patients with biliary tract stones

\begin{tabular}{|c|c|c|c|c|}
\hline \multirow[b]{2}{*}{ Treatment group } & \multirow[b]{2}{*}{$\begin{array}{l}\text { Total number of } \\
\text { subjects (\%) }\end{array}$} & \multicolumn{3}{|c|}{ Mean $( \pm S E M)$} \\
\hline & & $\begin{array}{l}\text { Duration } \\
\text { (days) }\end{array}$ & $\begin{array}{l}\text { Infusion rate } \\
(\mathrm{ml} / \mathrm{h})\end{array}$ & $\begin{array}{l}\text { Initial stone } \\
\text { size }(\mathrm{mm}) \\
\text { (largest stone })\end{array}$ \\
\hline $\begin{array}{l}\text { Successful therapeutic procedures } \\
\text { Curative } \\
\text { Adjunctive } \\
\text { Partially successful }\end{array}$ & $\begin{array}{l}88(25 \cdot 6) \\
29(8 \cdot 5) \\
70(20 \cdot 4)\end{array}$ & $\begin{array}{c}7 \cdot 2(0 \cdot 8) \\
8 \cdot 4(1 \cdot 3) \\
14 \cdot 6^{*}(1 \cdot 7)\end{array}$ & $\begin{array}{l}4 \cdot 8(0 \cdot 2) \\
4 \cdot 8(0 \cdot 3) \\
4 \cdot 7(0 \cdot 2)\end{array}$ & $\begin{array}{l}11 \cdot 0(1 \cdot 1) \\
11 \cdot 6(1 \cdot 0) \\
17 \cdot 0^{*}(1 \cdot 6)\end{array}$ \\
\hline $\begin{array}{l}\text { Unsuccessful therapeutic procedures } \\
\text { Stones unresponsive } \\
\text { Side effects causing study to be aborted }\end{array}$ & $\begin{array}{c}124(36 \cdot 2) \\
32(9 \cdot 3)\end{array}$ & $\begin{array}{l}8 \cdot 3(0 \cdot 6) \\
2 \cdot 1(0 \cdot 3)\end{array}$ & $\begin{array}{l}4.9(0.3) \\
4.2(0.4)\end{array}$ & $\begin{array}{r}13 \cdot 1(1 \cdot 2) \\
8 \cdot 8(1 \cdot 2)\end{array}$ \\
\hline
\end{tabular}


phatase showed no consistent change.

\section{SIDE EFFECTS OF MONO-OCTANOIN INFUSION}

Side effects occurred in $67 \%$ of patients, and indeed, $41 \%$ of subjects had multiple side effects (Table 4). Abdominal pain was the most common side effect and was the usual cause of aborted therapy. Pain was of three types. Most commonly it was described as burning in nature, was neither dose related, nor associated with increased biliary pressure. In some individuals, biliary type pain developed and was associated with increased manometric pressures. It was relieved by reducing the infusion rate. In a few individuals, severe acute biliary colic was precipitated by the infusion. This was assumed to be caused by impaction or passage of calculi at the ampulla of Vater.

Nausea, vomiting, and diarrhoea were usually also dose related and responded to a reduction in the infusion rate. Fever occurred during the course of the infusion in 18 subjects. This was attributed to cholangitis, and bile cultures were positive in 15 of these patients. The usual organisms were enterobacteria, most commonly $E$ coli and Strep faecalis. Pseudomonas and Klebsiella were cultured in a few cases. Infection with multiple organisms was common.

Severe side effects occurred in only 12 patients $(5 \%)$. Life threatening haemorrhage from duodenal ulceration developed in one patient. Acute pancreatitis, probably because of gall stone impaction, occurred in two patients. Obstructive jaundice also caused by impaction at the ampulla developed in a further three subjects. One patient in whom an overflow manometer was inadvertently omitted developed acute pulmonary oedema. Another patient with cirrhosis developed systemic acidosis and encephalopathic signs. ${ }^{36}$ One patient had an

Table 4 Side effects of mono-octanoin infusion

\begin{tabular}{lll}
\hline Complication & $\begin{array}{l}\text { Total number of } \\
\text { patients }(\%)^{*}\end{array}$ & $\begin{array}{l}\text { Patients who } \\
\text { discontinued therapy } \\
(\%)(\text { no) }\end{array}$ \\
\hline Abdominal pain & $137(39 \cdot 9)$ & $15(4 \cdot 4)$ \\
Nausea & $87(25 \cdot 3)$ & $13(3 \cdot 8)$ \\
Vomiting & $51(14 \cdot 9)$ & $7(2 \cdot 0)$ \\
Diarrhoea & $55(16 \cdot 0)$ & $1(0 \cdot 3)$ \\
Fever & $18(5 \cdot 2)$ & $3(0 \cdot 9)$ \\
Other $\dagger$ & $27(7 \cdot 9)$ & $6(1 \cdot 7)$ \\
\hline
\end{tabular}

* Sum of percentages exceeds $100 \%$ because some patients had more than one complication.

$\dagger$ This includes: anorexia (9 patients), lethargy (2), pancreatitis (2), pruritis (2), duodenal ulcer (1), allergic reaction (1), headache (1), depression (1), fatigue (1), hypokalemia (1). leucopenia (1), 'bile shock' (1), increased drainage from choledochoduodenal fistula (1). anaphylactoid reaction characterised by wheezing, rash, and hypotension. Septicaemia occurred in four patients. Leucopenia occurred in one patient.

Despite the variety and frequency of side effects, and despite the frail condition of many of the patients, no deaths were associated with monooctanoin infusion in these case reports.

\section{Discussion}

This study shows that mono-octanoin infusion is a moderately effective and usually safe treatment for bile duct calculi. This conclusion has also been stated by other authors, as noted, but previous studies have been based on much smaller patient samples.

The major deficiencies of this study are the lack of a control group and its multicentre basis. Less than one half of authorised physicians submitted case reports, and we cannot be certain that the response of the patients who were reported was identical to those who were not reported. A placebo group was not justified ethically. Spontaneous passage of moderately sized calculi from the biliary tree is unlikely, but some of the successful treatments were undoubtedly due to the flushing effect of the solvent per se. ${ }^{14}$

The results indicate that the common bile duct was cleared of stones in $34 \%$ of patients, either by mono-octanoin alone or by a combination of infusion therapy and an endoscopic or percutaneous procedure. Results with mono-octanoin are better than the results reported by others for sodium cholate $^{8-11}$ or heparin solution. ${ }^{13}{ }^{14}$ Only one controlled study has been done; Velasco et al $^{14}$ showed that mono-octanoin is more effective than heparinised saline for dissolution of bile duct stones. The success rate might have been greater if treatment had been continued for longer in the group in whom treatment was only partially effective.

The efficacy of mono-octanoin infusion for retained bile duct stones is clearly less than that of endoscopic, percutaneous, or surgical techniques. The efficacy of these procedures cannot be compared with that of solvent infusions because the mono-octanoin was used when these alternatives had either failed or were not possible. Infusion therapy was frequently used in the frail and elderly, and in these subjects, most of whom had previously undergone biliary surgery, the operative mortality would be anticipated to be quite high. ${ }^{37} \mathrm{~A}$ success rate of $34 \%$ with no mortality and a serious complication rate of $5 \%$ should be compared with the appreciable mortality of common duct exploration in subjects at high surgical risk.

Side effects were very frquent, but often resolved 
when the infusion rate was decreased. Monooctanoin directly damages the gastric and biliary epithelium of experimental animals, ${ }^{38-40}$ and has been reported to cause mild mucosal irritation ${ }^{23} 27$ and possibly ulceration of the bile duct ${ }^{41}$ in man. The drug therefore should be used with caution in subjects known to have peptic ulcer disease or in whom ischaemic bowel disease is suspected. Possibly the value of a mucosal protective agent, such as sucralfate, should be tested in a controlled study.

Systemic acidosis and encephalopathy have been reported in a patient with severe parenchymal liver disease who received mono-octanoin. ${ }^{36}$ Presumably impaired hepatic uptake and/or oxidation of its hydrolysis product, octanoate, resulted in a greater load of octanoate into the systemic circulation.

In other patients, abdominal pain was produced by biliary tract distension. Such patients were unable to tolerate even very low rates of infusion and hourly aspiration and bolus injections of monooctanoin is an alternative treatment regimen in these individuals.

Other side effects were probably caused by the problems of the infusion technique, rather than the infusion material. Pancreatitis, obstructive jaundice, cholangitis, and septicaemia were almost certainly caused by gall stone impaction at the ampulla of Vater rather than by mono-octanoin itself, and possibly they could have been prevented by more careful monitoring of the biliary pressure. Crabtree and coworkers have reported a case of necrotising choledochomalacia after mono-octanoin was infused into the common duct of a patient with a common duct stone which appeared to have been obstructing the distal common duct intermittently. ${ }^{42}$

The major factor decreasing efficacy when stones are effectively rinsed by solvent should be stone composition. As many as $40 \%$ of duct stones contain a major proportion of calcium salts, ${ }^{43}$ and treatment is likely to be ineffective in these. Alternating mono-octanoin with a solution of a chelating agent has been proposed by Leuschner et $a l^{41}{ }^{44}$ and may be effective for calcium-containing stones. Controlled studies with this regimen, however, are lacking. Recently, Allen et al from the Mayo Clinic have reported that tert butyl methyl ether is a far more potent gall stone solvent than mono-octanoin, ${ }^{45}$ and have reported more rapid dissolution of retained gall bladder stones in one patient and bile duct stones in another patient without significant side effects. ${ }^{46}$ In these patients, the stones dissolved in less than 24 hours.

Thus, mono-octanoin is at present the solvent of choice, even though more effective and acceptable gall stone dissolution agents may well become available in the future. There appear to be two indications for mono-octanoin at present: the first is when endoscopic, percutaneous, or surgical methods have failed or are not feasible; the second is during the time interval immediately after cholecystectomy before a mature sinus tract is formed around the T-tube in patients in whom sphincterotomy is not possible or if done, did not induce stone passage. Further studies are needed to define the safety and efficacy of mono-octanoin or other solvents in this particular group of patients.

This work was supported by NIH grants AM 21506 and grants-in-aid from Stokely Van Camp, Inc. and Ascot Pharmaceuticals, Inc.

\section{References}

1 Dowling RH. Management of stones in the biliary tree. Gut 1983; 24: 599-608.

2 Walker JW. The removal of gallstones by ether solution. Lancet $1891 ; 1: 874-5$.

3 Pribram BOC. The method for dissolution of common duct stones remaining after operation. Surgery 1947; 22: 806-18.

4 Strickler JH, Adkins DC, Rice CO. Ether flush treatment of retained postoperative common duct stones; local survey. Minnesota Med 1954; 37: 490-7.

5 Glenn F. Discussion comments following Way $\mathrm{LW}$, Admirand WH, and Dunphy JE. Management of choledocholithiasis. Ann Surg 1972; 176: 347-59.

6 Admirand WH, Way LW. Medical treatment of retained gallstones. Trans Assoc Am Phys 1972; 85: 382-7.

7 Way LW, Admirand WH, Dunphy JE. Management of choledocholithiasis. Ann Surg 1972; 176: 347-59.

8 Lansford C, Mehta S, Kern F Jr. The treatment of retained stones in the common bile duct with sodium cholate infusion. Gut 1974; 15: 48-51.

9 Franke F. Aufloesung zuruckgelassener choledochussteine mit Gallensaeure. Chir Praxis 1979; 25: 645-51.

10 Toouli J, Jablonski P, Watts JMcK. Dissolution of stones in the common bile duct with bile-salt solutions. Aust N Z J Surg 1974; 44: 336-40.

11 Britton DC, Gill BS, Taylor RMR, James O. The removal of retained gallstones from the common bile duct. Experience with sodium cholate infusion and the Burhenne catheter. Br J Surg 1975; 62: 520-3.

12 Catt PB, Hogg DF, Clunie GJA, Hardie IR. Retained biliary calculi: removal by a simple, non-operative technique. Ann Surg 1974; 180: 247-51.

13 Gardner B. Experiences with the use of intracholedochal heparinized saline for the treatment of retained common duct stones. Ann Surg 1973; 177: 240-4.

14 Velasco N, Braghetto I, Csendes A. Treatment of retained common bile duct stones: a prospective controlled study comparing mono-octanoin and heparin. World J Surg 1983; 7: 266-70. 
15 Mack E, Saito C, Goldfarb S, Carlson GL, Hofmann AF. Local toxicity of T-tube-infused cholate in the rhesus monkey. Surg Forum 1977; 28: 408-9.

16 Thistle JL, Carlson GL, Hofmann AF, LaRusso NF, MacCarty RL, Flynn GL, Higuchi WI, Babayan VK. Monooctanoin, a dissolution agent for retained cholesterol bile duct stones: physical properties and clinical application. Gastroenterology 1980; 78: 101622.

17 Flynn GL, Shah Y, Prakongpan S, Kwan KH, Higuchi WI, Hofmann AF. Cholesterol solubility in organic solvents. J Pharm Sci 1979; 68: 1090-7.

18 Hofmann AF, Schmack B, Thistle JL, Babayan VK. Clinical experience with monooctanoin for dissolution of bile duct stones. An uncontrolled multicenter trial. Dig Dis Sci 1981; 26: 954-5.

19 Gadacz RT. The effect of mono-octanoin on retained common bile duct stones. Surgery 1981; 89: 527-31.

20 Jarrett LN, Balfour TW. Intraductal infusion of monooctanoin: experience in 24 patients with retained common duct stones. Lancet 1981; 1: 68-70.

21 Mack E, Crummy AB, Babayan VK. Percutaneous transhepatic dissolution of common bile duct stones. Surgery 1981; 90: 584-7.

22 Mack E, Patier F, Crummy AB, Hofmann AF, Babayan VK. Retained biliary tract stones. Arch Surg 1981; 116: 341-4.

23 Schenk J, Schmack B, Riemann JF, Roesch W. Treatment of choledocholithiasis using the transpapillary perfusion technique. Endoscopy 1980; 12: 223-7.

24 Venu RP, Geenen JE, Toouli J, Hogan WJ, Koslov N, Stewart ET. Gallstone dissolution using mono-octanoin infusion through an endoscopically placed nasobiliary catheter. Am J Gastroenterol 1982; 77: 227-30.

25 Uribe M, Uscanga L, Sarca S, Sanjurjo JL, La Garriga $\mathrm{J}$, Oritz JH. Dissolution of cholesterol ductal stones in the biliary tree with medium chain glycerides. Dig Dis Sci 1981; 76: 636-40.

26 Witzel L, Wiederholt J, Wolbergs E. Dissolution of retained duct stones by perfusion with mono-octanoin via a teflon catheter introduced endoscopically. Gastrointest Endoscopy 1981; 27: 63-5.

27 Tritapepe R, DiPadova C, Pozzoli M, Rovagnati P, Montorsi W. The treatment of retained biliary stones with monooctanoin: report of 16 patients. Am J Gastroenterol 1984; 79: 710-4.

28 Leuschner U, Baumgaertel H, Wurbs D. Aufloesung von Cholesterin-Gallengangssteinen mit einer modifizerten Capmul 8210-Emulsion und einer EDTAGallensalzloesung. Leber Magen Darm 1980; 10: 284 7.

29 Steinhagen RM, Pertsemlidis D. Monooctanoin dissolution of retained biliary stones in high risk patients. Am J Gastroenterol 1983; 78: 756-60.

30 Bogardus JB. Importance of viscosity in the dissolution rate of cholesterol in monooctanoin solutions. J Pharm Sci 1984; 73: 906-10.

31 Schwabe AD, Cozzetto FJ, Bennett LR, Mellinkoff SM. Estimation of fat absorption by monitoring of expired radioactive carbon dioxide after feeding a radioactive fat. Gastroenterology 1962; 42: 285-91.

32 Scheig R. Hepatic metabolism of medium chain fatty acids. In: Senior JR, ed. Medium chain triglycerides. Philadelphia: University of Pennsylvania Press, 1968: 39-50.

33 Bogardus JB. Unusual cholesterol solubility in water/ glyceryl-1-monooctanoate solutions. J Pharm Sci 1982; 71: $370-2$.

34 vanSonnenberg E, Schiffman HR, Casola G, Talner LB, Reznek RH. Simplified solvent infusion and drainage in closed systems: double lumen single catheter method. Am J Radiol 1985; 144: 259-60.

35 Teplick SK, Haskin PH. Monooctanoin perfusion for in vivo dissolution of biliary stones. A series of 11 patients. Radiology 1984; 153: 379-83.

36 Minuk GY, Hoffnagle JH, Jones EA. Systemic side effects from the intrabiliary infusion of mono-octanoin for the dissolution of gallstones. J Clin Gastroenterol 1984; 4: 133-5.

37 Fitzpatrick G, Neutra R, Gilbert JP. Cost-effectiveness of cholecystectomy for silent gallstones. In: Bunker JP, Barnes BA, Mosteller F, eds. Costs, risks, and benefits of surgery. New York: Oxford University Press, 1977: 246-61.

38 Goetz R, Raedsch R, Waldherr R, Walker S, Stiehl A, Kommerell B. Lokal toxische Wirkung von Glyceriloctanoat-Praeparationen. Z Gastroenterol 1981; 19: 549-50.

39 Schenk J, Koch H, Stolte M, -Schmack B. Tissue compatibility of the gallstone solubilizer Capmul 8210 a study in cats. [Abstract]. Gastroenterology 1979; 76: 1237.

40 Leuschner U, Sieratzki J, Klempa I, Baumgaertel H, Lang S, Siede W, Huebner K, Classen M. Investigations on the toxicity of bile salt solutions, Capmul 8210 and a bile salt-EDTA solution for common bile duct perfusion in dogs. Digestion 1984; 30: 23-32.

41 Leuschner U, Baumgaertel $\mathrm{H}$. Chemical dissolution of common bile duct stones. In: Okuda K, Nakayama F, Wong J, eds. Intrahepatic calculi. New York: Alan R Liss, 1984: 193-225.

42 Crabtree TS, Dykstra M, Kelly J, Preshaw RM. Necrotizing choledochomalacia after use of monooctanoin to dissolve bile-duct stones. Canad J Surg 1982; 25: 644-6.

43 Wosiewitz U, Schenk J, Sabinski F, Schmack B. Investigations on common bile duct stones. Digestion 1983; 26: 43-52.

44 Leuschner U, Baumgaertel H. Gallstone dissolution in the biliary tract: In vitro investigations on inhibiting factors and special dissolution agents. Am J Gastroenterol 1982; 77: 222-6.

45 Allen MJ, May GR, Borody TJ, LaRusso NF, Thistle JL. Methyl tertiary butyl ether rapidly dissolves gallstones in vitro and in vivo. [Abstract]. Hepatology 1983; 3: 809 .

46 Allen MJ, Borody TJ, Bugliosi TF, May GR, LaRusso NF, Thistle JL. Rapid dissolution of gallstones in humans using methyl tert-butyl ether. N Engl J Med 1985; 312: 217-20. 